\title{
Polymelia and polydactyly in white stork (Ciconia ciconia)
}

\begin{abstract}
We report polymelia and polydactyly in an immature White Stork (Ciconia ciconia). Polymelia and polydactyly are unusual leg malformations and have been rarely recorded in birds. To our knowledge there is no study indicating the two cases observed in the same bird. We observed a White Stork which has two pairs of fused legs, with a total of nine and 10 toes on left and right fused legs respectively. Here, we describe the observed malformations and evaluate potential causes.
\end{abstract}

Keywords: leg malformations, polydactyly, hydra syndrome, polymelia, stork immature
Volume 2 Issue 3 - 2017

\author{
Ortaç Onmuș,' Mehmet Siki,' Orhan Gül,' \\ Osman Yelken ${ }^{2}$ \\ 'Department of Biology, Ege University, Turkey \\ ${ }^{2}$ VetMed, Municipality of Selçuk District, Turkey
}

Correspondence: Ortaç Onmuș, Department of Biology, Faculty of Sciences, Ege University, Natural History Museum, Research and Application Center, Izmir, Turkey, Email ortac.onmus@ege.edu.tr

Received: June 01, 2017| Published: July 25, 2017

\section{Case presentation}

Polymelia is a congenital anomaly, generally known as the hydra syndrome and is defined as the development of extra limbs. Polymelia may occur due to various factors such as genetic factors including tamogenes, chromosomes, ${ }^{1}$ exposure to toxic or radioactive chemicals ${ }^{2}$ and vitamins. ${ }^{3}$ Polymelia may also be observed due to incorrect splitting of limbs or the re-absorbance of a conjoined twin back into the body. ${ }^{4}$ Polymelia has been mainly reported in humans ${ }^{5,6}$ but also in some other animals, such as farm animals like cattle and frogs. ${ }^{7-9}$ Unlike other animals, polymelia is a rare phenomenon observed in birds. So far it has been reported mainly among broiler chickens and other farming fowls. ${ }^{10}$ The only reported case on wild birds is Swainson's hawk (Buteo swainsoni). ${ }^{11}$

Similar to polymelia, polydactyly is more frequently observed in farm animals such as livestock farming. Polydactyly may occur due to similar reasons causing polymelia. ${ }^{12}$ Polydactyly was reported so far on Vaux's Swift Chaetura vauxi ${ }^{13}$ screech owls Otis asio and pigeons, ${ }^{14}$ as well. We report polymelia and polydactyly in an immature White Stork (Ciconia ciconia). We observed the White Stork during our regular banding operations that we are carrying out in the Aegean Region of Turkey. So far we have banded more than 1200 white stork immature and have never observed such a phenomenon before. In the literature there is no case report of a White Stork having polymelia or polydactyly. This is the first case reported.

\section{Discussion}

The general appearance of the juvenile White Stork (Ciconia ciconia) having polymelia and polydactyly is given in (Figure 1). The White Stork had two pairs of fused legs, with a total of nine toes on the left leg and 10 toes on the right. The other two siblings and other 89 immature white storks from the neighborhood were normal on orthopedic examination. The stork was macroscopically and radio graphically examined. Plain X-ray images of both left and right legs are given in (Figure $2 \& 3$ ) respectively. After investigation the White Stork was released back to its nest which was located at the city center. After the release we regularly monitored the nest and the white stork from a distance by using field scopes. The White Stork with the anomaly was observed to have difficulties standing up. About three weeks later the White Stork was infanticide by its parents. Both Black and White Storks were observed practicing facultative parental infanticide. Brood reduction may happen due to various reasons such as existence of sick and injured immature, inadequate food supply, and excessive number of offspring's. ${ }^{15}$

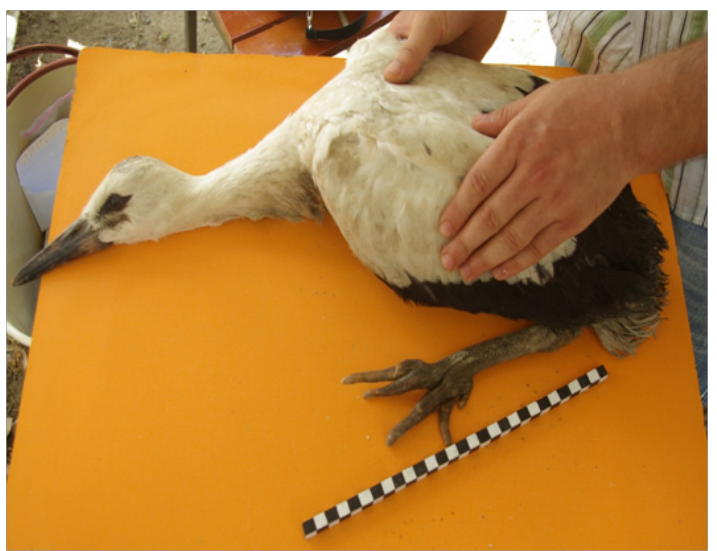

Figure I General appearance of the juvenile White Stork (Ciconia ciconia) Both polymelia and polydactyly is evident. A stick with black and white color whose segments corresponding to a $\mathrm{Icm}$ is given for visual comparison.

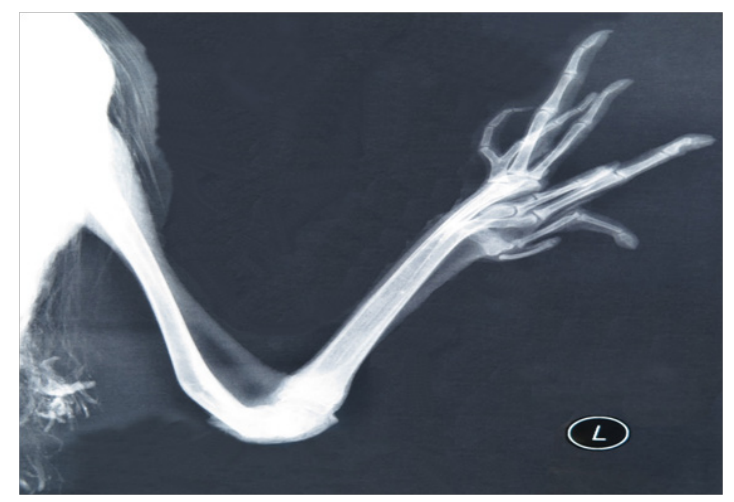

Figure 2 Plain X-ray images of the left fused legs of the juvenile White Stork (Ciconia ciconia). Polymelia and polydactyly are clearly observed on the x-ray image. 


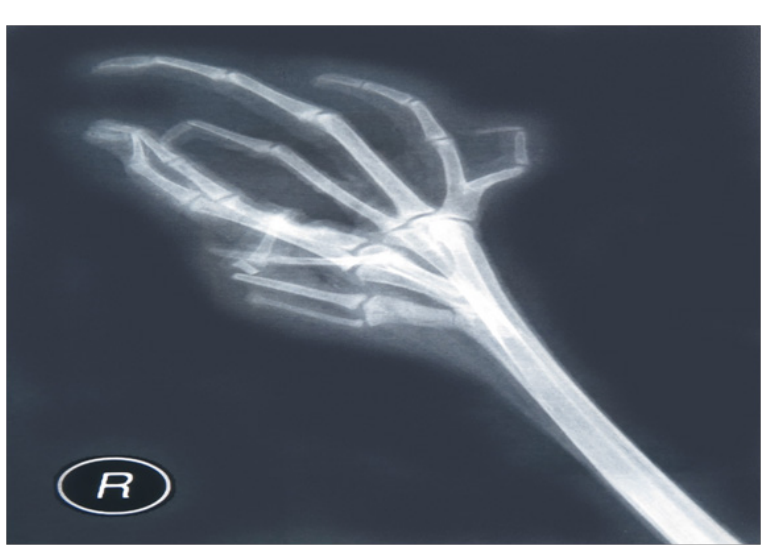

Figure 3 Plain X-ray images of the right leg of the juvenile White Stork (Ciconia ciconia). The image is showing only the right fused legs of the White Stork. Right leg had a formation of a pair of fused legs, with a total number of 10 toes, which can be clearly observed on the x-ray image.

Developmental malformations in avian species have clearly been summarized by ${ }^{16}$ Pourlis stated that the malformations of the birds reflect the status of their health as well as the status of their habitat. The region where the malformed White Stork was identified is on general very healthy countryside in terms possible toxic or hazardous chemical contaminants, as the two main sources of the income of the people living in the region depend on peach farming and tourism. Besides, the region is not densely populated, only low-density urbanized. The existing industry in the region is a very small scale and only to meet daily needs of local people. Therefore we expect that the reason of this malformation is possibly not due to exposure to toxic or radioactive chemicals but possibly due to genetics factors, if we do not take the consideration of the fact that this possible exposure might have happened during migration and or wintering period of its parent(s). To investigate possible reasons, we have collected fresh blood specimens from the bird and its siblings. We also took the dead malformed individual and stored in a special freezer for further analysis. However, the identification of these malformations requires detailed studies with expertise in diverse subjects and my take very long time but the causes of most congenital malformations are still unknown. Therefore, in this study our aim was to share this observation with the scientific community.

\section{Acknowledgements}

We thank to the Department of Radiology of the Medical School of Ege University for taking X-ray images and the Municipality of Selçuk District of Izmir and its employees who have contributed the bird banding operations.

\section{Conflict of interest}

The author declares no conflict of interest.

\section{References}

1. Nowacka J, Urbaniak K, Antosik P, et al. Polymelia associated with frequent chromosome breaks in a heifer. Vet Rec. 2007;161:276-277.

2. Albers PH, Hoffman DJ, BrisbinIL. Unusual leg malformations in screech owls from a South Carolina Superfund site. J Toxicol Environ Health A. 2001;63(2):89-99.

3. Bruschelli GM, Rosi G. Polymelia induced by vitamin A in larvae of Bufo vulgaris. Rivista di Biologia. 1971;64(3/4):271-283.

4. Kim C, Yeo S, Cho G, et al. Polymelia with Two Extra Forelimbs at the Right Scapular Region in a Male Korean Native Calf. J Vet Med Sci. 2001;63(10):1161-1164.

5. Verma S, Khanna M, Tripathi VN, et al. Occurrence of Polymelia in a Female Child. J Clin Imaging Sci. 2013;3:18.

6. Abu-Seida AM. Amputation of Polymelia in a Layer Chicken. Avian Dis. 2014;58(2):330-332.

7. Hiraga T, Dennis SM. Congenital Duplication. Vet Clin North Am Food Anim Pract. 1993;9(1):145-161.

8. Rousseaux CG, Ribble CS. Developmental anomalies in farm animals: II Defining etiology. The Canadian Veterinary Journal. 1988;29:30-40.

9. Zieliński P. Brood reduction and parental infanticide-are the White Stork Ciconia ciconia and the Black Stork C. nigra exceptional? Acta Ornithologica. 2002;37(2):113-119.

10. Azeez OI, Oyagbemi AA. First report of polymelia and a rudimentary wing in a Nigerian Nera black chicken. J S Afr Vet Assoc. 2013;84(1):1-3.

11. Rogers KH, Mete A, McMillin S, et al. Polymelia and Syndactyly in a Swainson's Hawk (Buteo swainsoni). Journal Of Wildlife Diseases. 2016;52(1):114-117.

12. Pont SJ, Robbins JM, Bird TM, et al. Congenital malformations among liveborn infants with trisomies 18 and 13. Am J Med Genet A. 2006;140(16):1749-1756.

13. Sakai WH. Polydactyly in a Vaux's Swift. The Wilson Journal of Ornithology. 2006;118(3):424-426.

14. Hollander WF, Levi WM. Polydactyly, a sub-lethal character in the pigeon. Journal of Heredity. 1942;33(11):385-391.

15. ZuckerSA, Root MV, Johnston SD. Diphallia and polymelia in a dog. Canine practice. 1993.

16. Pourlis AF. Developmental malformations in avian species: Manifestations of unknown or genetic etiology-A review. Asian J Anim Vet Adv. 2011;6:401-415. 